\title{
Trends in serum relaxin concentration among elite collegiate female athletes
}

This article was published in the following Dove Press journal:

International Journal of Women's Health

I 8 January 201 I

Number of times this article has been viewed

\author{
Jason L Dragoo' \\ Tiffany N Castillo' \\ Tatiana A Korotkova' \\ Ashleigh C Kennedy' \\ Hyeon Joo Kim' \\ Dennis R Stewart ${ }^{2}$ \\ 'Department of Orthopaedic Surgery, \\ Stanford University, Palo Alto, \\ CA, USA; ${ }^{2}$ Corthera Inc. \\ San Mateo, CA, USA
}

Purpose: This study was designed to investigate the relationship between serum relaxin concentration (SRC) and menstrual history and hormonal contraceptive use among elite collegiate female athletes. Evaluation of SRC in athletes is necessary, because relaxin has been associated with increased knee joint laxity and decreased anterior cruciate ligament (ACL) strength in animal models.

Methods: National Collegiate Athletic Association Division I female athletes participating in sports at high risk for ACL tears - basketball, field hockey, gymnastics, lacrosse, soccer, and volleyball - were invited to participate. All participants completed a questionnaire about their menstrual history and hormonal contraceptive use. Venipuncture was performed to obtain samples of serum progesterone and relaxin. Samples were obtained during the mid-luteal phase from ovulating participants, and between the actual or projected cycle days 21 to 24 , from anovulatory participants. Serum concentration of relaxin and progesterone was determined by ELISA and the data were analyzed using SPSS statistical software with significance set at $P=0.05$.

Results: 169 female athletes participated. The mean SRC among all participants was $3.08 \pm 6.66 \mathrm{pg} / \mathrm{mL}$ ). The mean SRC differed significantly between those participants using hormonal contraceptives $(1.41 \mathrm{pg} / \mathrm{mL})$ and those not using hormonal contraceptives $(3.08 \mathrm{pg} / \mathrm{mL}$, $P=0.002)$. Mean SRC was lowest among amenorrheic participants $(1.02 \mathrm{pg} / \mathrm{mL})$ and highest among oligomenorrheic participants $(3.71 \mathrm{pg} / \mathrm{mL})$ and eumenorrheic participants $(3.06 \mathrm{pg} / \mathrm{mL})$; these differences were not significant $(P=0.53)$. Mean serum progesterone concentration (SPC) differed significantly between those participants using hormonal contraceptives $(2.80 \mathrm{ng} / \mathrm{mL})$, and those not using hormonal contraceptives $(6.99 \mathrm{ng} / \mathrm{mL}, P<0.0001)$.

Conclusions: There is a positive correlation between serum progesterone and SRC and an attenuation of SRC with hormonal contraceptive use. Our results underscore the significant role that hormonal contraceptives can play in decreasing relaxin levels, if future investigations establish a link between relaxin levels and ligamentous injury among female athletes.

Keywords: hormones, ACL, anterior cruciate ligament, hormonal contraceptives, menstrual cycle

\section{Introduction}

Relaxin is a peptide hormone that belongs to the insulin superfamily of hormones. ${ }^{1,2}$ Recent research on this hormone has revealed that it has three forms in humans, ${ }^{3}$ which have unique sites of production ${ }^{4-6}$ and a broad range of physiologic effects throughout the body. The focus of this study is on Relaxin-2, which is produced by the corpus luteum, ${ }^{7}$ decidua, ${ }^{8-10}$ and placenta ${ }^{6,10}$ and is transcriptionally regulated by progesterone and glucocorticoid hormones. ${ }^{11}$ Relaxin-2 has historically been studied in pregnant
Correspondence: Jason L Dragoo, 450 Broadway, MC 6342,

Redwood City, CA 94063, USA

Tel + I $65072 \mid 7800$

Fax + I $65072 \mid 3470$

Email jdragoo@stanford.edu submit your manuscript | www.dovepress.com

Dovepress

DOI: $10.2147 / 1 \mathrm{JWH} . S|4| 88$
(C) 201 I Dragoo et al, publisher and licensee Dove Medical Press Ltd. This is an Open Access article which permits unrestricted noncommercial use, provided the original work is properly cited. 
women. Because it is also found in the serum of nonpregnant women, ${ }^{12-14}$ its effects on nonreproductive tissue merits further investigation.

Research has established that the function of Relaxin-2 is to facilitate the remodeling of collagen through the upregulation of collagenases, ${ }^{15,16}$ matrix metalloproteinases, ${ }^{17}$ and tissue plasminogen activator (tPA). ${ }^{15,17}$ Because of its well-established role as a female reproductive hormone, the collagenolytic effects of Relaxin-2 have been studied primarily with respect to its effect on pregnancy and parturition, ${ }^{18,19}$ myometrial pathology, ${ }^{20}$ urinary incontinence, ${ }^{21}$ and premenstrual dysphoric disorder ${ }^{22}$ in middle-aged women. More recently, a number of studies have begun to investigate the role of relaxin in nonreproductive organ and tissue disease processes. $^{23-26}$

Relaxin has been associated with increased knee joint laxity in pregnant women ${ }^{27}$ and decreased anterior cruciate ligament (ACL) strength in animal models. ${ }^{28}$ The established presence of relaxin receptors on the female $\mathrm{ACL}^{29,30}$ also underscores that relaxin-mediated remodeling of female ligaments is an important mechanism to investigate. To date, no studies have described the serum relaxin concentration (SRC) among a large sample of young, healthy, nulligravidae elite female athletes. Understanding SRC among this population is important, because relaxin has been shown to increase ligament laxity among women. ${ }^{27,31,32}$

This study was designed to investigate the relationship between SRC and menstrual history and hormonal contraceptive use among elite collegiate female athletes. Our hypothesis is that athletes who are on hormonal contraceptives, or who are amenorrheic, will have significantly lower levels of relaxin than those who are not on hormonal contraceptives or those who are eumenorrheic or oligomenorrheic, because these athletes will be anovulatory and not producing the corpus luteum thought to be necessary to secrete Relaxin-2.

\section{Methods}

After institutional review board approval was obtained, National Collegiate Athletic Association Division I female athletes who participate in sports identified as high risk for ACL tears - basketball, field hockey, gymnastics, lacrosse, soccer, and volleyball - were recruited to participate. Athletes with a history of pregnancy were ineligible to participate. Of the approximately 190 eligible athletes, 169 agreed to participate ( $89 \%$ response rate). The desired sample size was at least 90 , to reach $80 \%$ power to detect a $10 \%$ difference in mean SRC between 2 groups.
All participants completed a questionnaire on their demographic information, menstrual history, pregnancy history, and hormonal contraceptive use. This information was verified by review of participant medical records. Urine luteinizing hormone ( $\mathrm{LH})$ testing was used to confirm when to obtain blood samples from the participants, because samples had to be obtained during the mid-luteal phase of the menstrual cycle when relaxin is known to peak. ${ }^{8,13}$ Participants who reported being eumenorrheic (10-12 menstrual periods per year) or oligomenorrheic (5-9 menstrual periods per year), and who were not on any form of hormonal contraception, underwent selftesting with urine LH detection tests (Ovulation Midstream Tests, Early-pregnacy-tests.com, Bellingham, WA, USA) to determine the date of their LH surge. LH testing was conducted for 5 days on average starting 2 days before the anticipated date of ovulation. If a positive LH test was not obtained during the first round of testing, more tests were given for a longer timeframe during the subsequent menstrual cycle and the testing start date was adjusted, based on the newly determined cycle length. Once participants had reported a positive LH test, they were scheduled for a blood draw 7 to 10 days after the date of the positive $\mathrm{LH}$ test, which is the mid-luteal window when the relaxin surge is expected to occur.

Participants who reported being amenorrheic (4 or fewer menstrual cycles per year) did not undergo LH testing since they were assumed to be anovulatory. Instead, amenorrheic participants were scheduled for a blood draw 21 to 24 days after they were projected to have had their last menstrual period (LMP). The projected day zero of their LMP was based on a forward calculation of assuming regular cycles from their last confirmed LMP. Participants who reported being on a form of hormonal contraception to suppress ovulation, regardless of their menstrual history, were scheduled to have their blood taken 21 to 24 days after the start of their LMP. Urine pregnancy tests (hCG Midstream Tests, Early-pregnacy-tests.com, Bellingham, WA, USA) were given when blood was taken, to verify that participants were not pregnant.

Venipuncture was performed using a BD Vacutainer Blood Collection System and approximately 3 to $4 \mathrm{~mL}$ of blood was collected. The plasma sample was left standing undisturbed at room temperature for 30 minutes to allow for adequate clotting. The sample was then placed in a centrifuge (Quest Diagnostics VanGuard V6500, Madison, NJ, USA) and spun for 15 minutes at $3000 \mathrm{rpm}$ to separate the serum and blood cell layers. After centrifugation, the serum was extracted by pipette and aliquotted into two $1-\mathrm{mL}$ 
samples in Nalgene vials. All serum samples were coded with unique identifiers to ensure that the lab technician was blinded to their content. All samples were stored at $80^{\circ} \mathrm{C}$ until analysis.

A Quantikine Human Relaxin-2 Immunoassay (DRL200, R\&D Systems Inc., Minneapolis, MN, USA) was used according to the manufacturer's protocol to determine the SRC of the samples. The intra-assay and inter-assay coefficients of variation for mean SRC $(34.4 \mathrm{pg} / \mathrm{mL}$ and $40.8 \mathrm{pg} / \mathrm{mL}$ ) were $4.7 \%$ and $10.2 \%$, respectively. The mean minimum detectable dose was $1 \mathrm{pg} / \mathrm{mL}$. All samples were run in triplicate and serum relaxin concentration values were calculated based on the standard curve, including the zero dose standard. The assay utilized the standard quantitative sandwich enzyme immunoassay technique.

A Progesterone ELISA (BQ 129S, BioQuant, San Diego, CA, USA) was used to determine the progesterone concentrations in the samples in order to verify that those who were on hormonal contraceptives did not have ovulatory cycles. The intra-assay and inter-assay coefficients of variation for mean progesterone concentration $(1.72 \mathrm{ng} / \mathrm{mL}$ and $2.16 \mathrm{ng} / \mathrm{mL}$ ) were $5.36 \%$ and $9.68 \%$, respectively. All samples were run in duplicate according to the manufacturer's protocol. The threshold for determining was a progesterone concentration of $3.3 \mathrm{ng} / \mathrm{mL}$, while $4.4 \mathrm{ng} / \mathrm{mL}$ was deemed the cut-off for determining mid-luteal phase.

ANOVA analysis was used to determine the difference between mean SRC and mean progesterone, based on menstrual history (eumenorrheic, oligomenorrheic, and amenorrheic) and $t$ tests were used to determine differences between groups based on hormonal contraceptive use and ovulatory status. Pearson correlations were done to assess the relationship between relaxin and progesterone, as well as between body mass index (BMI) and relaxin. Significance was set at $P=0.05$.

\section{Results}

All 169 participants (23 from basketball, 24 from field hockey, 39 from gymnastics, 38 from lacrosse, 24 from soccer, and 21 from volleyball) provided adequate blood samples for analysis. The mean age of participants was $19.49 \pm 1.34$ years. The mean BMI was $22.42 \pm 1.83$ There was no significant correlation between BMI and SRC ( $r=0.02, P=0.81)$ and no significant correlation between BMI and progesterone levels $(r=0.03, P=0.67)$. Overall, the majority $(123,72.8 \%)$ of participants were eumenorrheic, $36(21.3 \%)$ were oligomenorrheic, and $10(5.9 \%)$ were amenorrheic. The majority $(99,58.6 \%)$ of participants were not using a hormonal form of contraceptive compared with the 70 (41.4\%) who were using a form of hormonal contraceptive. Of the women on hormonal contraceptives, the vast majority used combination oral contraceptive (COC) pills, 2 were using the NuvaRing, and 1 was on a progesteroneonly contraceptive pill (Nora-BE). Of participants on COCs, $66 \%$ were on either Yasmin, Orthotricyclen Lo, Loestrin, or Trinessa, and the remainder were on either Zovia, Alesse, Desogen, Enpresse, Kavina, Diane-35, Ovcon, Fecon, Microgestin, OrthoEvra, Mycrogynon, TriSpintec, or Junel. Within the hormonal contraceptive-using group, 4 (6\%) were amenorrheic, 19 (29\%) were oligomenorrheic, and 43 (65\%) were eumenorrheic.

The mean SRC among all participants was $3.08 \pm$ $6.66 \mathrm{pg} / \mathrm{mL}$ (range, 0-50.38 pg/mL). Three participants had SRCs greater than 1 standard deviation (SD) above the mean $(>9.11 \mathrm{pg} / \mathrm{mL}), 3$ had SRCs greater than $2 \mathrm{SDs}$ above the mean $(>15.77 \mathrm{pg} / \mathrm{mL})$, and 2 had SRCs greater than 3 SDs above the mean $(>22.43)$. As outlined in Table 1, there was a significant difference between the mean SRC among participants using hormonal contraceptives $(1.41 \pm 3.50 \mathrm{pg} / \mathrm{mL})$ compared with those not using hormonal contraceptives $(4.25 \pm 8.02 \mathrm{pg} / \mathrm{mL}, P=0.002)$. ANOVA analysis revealed no statistically significant difference in mean SRC between the participants based on menstrual history $(P=0.53)$. However, the mean SRC was lowest among amenorrheic participants $(1.02 \pm 2.47 \mathrm{pg} / \mathrm{mL})$ and highest among oligomenorrheic participants $(3.71 \pm 8.86 \mathrm{pg} / \mathrm{mL})$ and eumenorrheic participants $(3.06 \pm 6.14 \mathrm{pg} / \mathrm{mL})$. Among the women not using hormonal contraceptives, there was a significant difference in SRC $(P=0.003)$ and in serum progesterone concentration $($ SPC $)(P<0.0001)$ when analyzed by ovulatory status.

The mean serum progesterone concentration (SPC) among all participants was $5.25 \pm 4.58 \mathrm{ng} / \mathrm{mL}$ (range, 1.09-18.84 ng/mL). There was a significant difference between mean SPC among participants using hormonal contraceptives $(2.80 \pm 1.76 \mathrm{ng} / \mathrm{mL})$ versus participants not using hormonal contraceptives $(6.99 \pm 5.15 \mathrm{ng} / \mathrm{mL}, P<0.0001)$. ANOVA analysis revealed no significant difference in mean SPC between participants based on menstrual history alone $(P=0.45)$. The mean SPC was lowest among amenorrheic participants $(3.53 \pm 2.20 \mathrm{ng} / \mathrm{mL})$, second lowest among oligomenorrheic participants $(5.13 \pm 4.93 \mathrm{ng} / \mathrm{mL})$, and highest among eumenorrheic participants $(5.43 \pm 4.62 \mathrm{ng} / \mathrm{mL})$. In the hormonal contraceptive group, 21 participants (30\%) had SPCs above the $3.3 \mathrm{ng} / \mathrm{mL}$ threshold for determining ovulation. Of the participants not using hormonal contraception, 
Table I Mean serum relaxin concentration, serum progesterone concentration, body mass index (BMI), and participant age

\begin{tabular}{|c|c|c|c|c|}
\hline & $\begin{array}{l}\text { Serum relaxin } \\
\text { concentration } \\
(\mathrm{pg} / \mathrm{mL})\end{array}$ & $\begin{array}{l}\text { Serum } \\
\text { progesterone } \\
\text { concentration } \\
(\mathrm{ng} / \mathrm{mL})\end{array}$ & BMI & $\begin{array}{l}\text { Participant age } \\
\text { (years) }\end{array}$ \\
\hline $\begin{array}{l}\text { All participants } \\
(N=169)\end{array}$ & $3.08 \pm 6.66$ & $5.25 \pm 4.58$ & $22.42 \pm 1.83$ & $19.49 \pm 1.34$ \\
\hline $\begin{array}{l}\text { No hormonal } \\
\text { contraceptive }(N=99)\end{array}$ & $4.25 \pm 8.02 *$ & $6.99 \pm 5.15 * *$ & $22.35 \pm 1.80$ & $19.11 \pm 1.20$ \\
\hline Ovulatory (7I) & $5.30 \pm 9.08^{\mathrm{a}}$ & $8.79 \pm 5.04^{b}$ & $22.28 \pm 1.78$ & $19.17 \pm 1.27$ \\
\hline Nonovulatory (28) & $1.61 \pm 3.08^{\mathrm{a}}$ & $2.42 \pm 0.49^{b}$ & $22.27 \pm 1.86$ & $18.96 \pm 1.04$ \\
\hline $\begin{array}{l}\text { Hormonal } \\
\text { contraceptive }(N=70)\end{array}$ & $1.41 \pm 3.50 *$ & $2.80 \pm 1.76 * *$ & $22.53 \pm 1.90$ & $20.01 \pm 1.35$ \\
\hline Ovulatory (2I) & $2.12 \pm 5.39$ & $4.88 \pm 1.85^{c}$ & $21.99 \pm 1.96$ & $19.62 \pm 1.28$ \\
\hline Nonovulatory (49) & $1.11 \pm 2.18$ & $1.91 \pm 0.54^{c}$ & $22.77 \pm 1.84$ & $20.18 \pm 1.35$ \\
\hline Amenorrheic $(N=10)$ & $1.02 \pm 2.47$ & $3.53 \pm 2.20$ & $22.15 \pm 2.22$ & $19.10 \pm 1.66$ \\
\hline Ovulatory (4) & $0.0 \pm 0.0$ & $5.47 \pm 2.40$ & $22.15 \pm 2.52$ & $19.0 \pm 2.0$ \\
\hline Nonovulatory (6) & $1.70 \pm 3.09$ & $2.23 \pm 0.46$ & $22.5 \mathrm{I} \pm 2.24$ & $19.17 \pm 1.60$ \\
\hline Oligomenorrheic $(\mathrm{N}=36)$ & $3.7 I \pm 8.86$ & $5.13 \pm 4.93$ & $21.98 \pm 1.61$ & $19.42 \pm 1.25$ \\
\hline Ovulatory (17) & $6.67 \pm 12.13$ & $8.48 \pm 5.5 I^{d}$ & $21.86 \pm 1.49$ & $19.53 \pm 1.28$ \\
\hline Nonovulatory (19) & $1.05 \pm 2.45$ & $2.14 \pm 0.55^{d}$ & $22.09 \pm 1.75$ & $19.32 \pm 1.25$ \\
\hline Eumenorrheic $(N=123)$ & $3.06 \pm 6.14$ & $5.43 \pm 4.62$ & $22.58 \pm 1.85$ & $19.54 \pm 1.34$ \\
\hline Ovulatory (7I) & $4.32 \pm 7.56^{\mathrm{e}}$ & $7.89 \pm 4.72^{f}$ & $22.40 \pm 1.86$ & $19.23 \pm 1.24$ \\
\hline Nonovulatory (52) & $1.33 \pm 2.54^{\mathrm{e}}$ & $2.06 \pm 0.60^{f}$ & $22.82 \pm 1.83$ & $19.96 \pm 1.36$ \\
\hline
\end{tabular}

Notes: $* P=0.002$, difference in mean serum relaxin concentration $(S R C)$; $* P<0.0001$, difference in mean serum progesterone concentration $(S P C)$; $P=0.003$, difference in mean SRC; ${ }^{b} P<0.000$ I, difference in mean SPC; ${ }^{c} P<0.000$ I, difference in mean SPC; ${ }^{d} P<0.000$, difference in mean SPC; ${ }^{e} P=0.003$, difference in mean SRC; ${ }^{f} P<0.000$ I, difference in mean SPC.

$28 \%$ had SPCs below the $3.3 \mathrm{ng} / \mathrm{mL}$ cutoff for ovulatory cycles; 2 amenorrheic, 14 oligomenorrheic, and 17 eumenorrheic participants had SPCs below the $4.4 \mathrm{ng} / \mathrm{ML}$ threshold for determining mid-luteal phase. Lastly, as depicted in Table 2, there was a significant correlation overall, and among noncontracepting, ovluatory, oligomenorrheic and eumennorheic participants, between serum progesterone and relaxin concentrations.

\section{Discussion}

This is the largest study to assess SRC among young, healthy, nulligravidae, elite collegiate female athletes. It is

Table 2 Pearson correlation between serum relaxin concentration and serum progesterone concentration

\begin{tabular}{lll}
\hline & $\begin{array}{l}\text { Correlation } \\
\text { coefficient }(\boldsymbol{R})\end{array}$ & P-value \\
\hline Overall & 0.49 & $<0.01$ \\
Amenorrheic & -0.13 & $0.7 \mathrm{I}$ \\
Oligomenorrheic & 0.63 & $<0.01$ \\
Eumenorrheic & 0.44 & $<0.01$ \\
Hormonal contraceptive & 0.01 & 0.93 \\
No hormonal contraceptive & 0.50 & $<0.01$ \\
Ovulatory & 0.45 & $<0.01$ \\
Nonovulatory & 0.21 & 0.07 \\
\hline
\end{tabular}

important to understand the SRC in this population because of the possible effect of relaxin on ligament stability among athletes. Since relaxin is involved in collagen remodeling, and collagen is an important structural element of ligaments, it is plausible that women with increased relaxin levels may have an increased risk of ligament injury, which could then make them more susceptible to injuries such as ACL rupture. Before investigating any correlation between these types of injuries and relaxin levels, however, further investigation of relaxin concentrations in this population is necessary.

We found that our sample of collegiate female athletes had a relatively low range of SRCs $(0-50.83 \mathrm{pg} / \mathrm{mL})$ compared with the SRCs reported by Arnold et al among a similar population of athletes $(291-616 \mathrm{pg} / \mathrm{mL}){ }^{33}$ The SRCs among our athletes were also lower than those reported by Stewart ${ }^{13}$ among women with nonconceptive cycles (30-150 pg/mL). Additionally, these SRCs were lower than those reported among older parous women by Binder et al (260-620 pg/mL, Santa Cruz Biotechnology Inc. assay), ${ }^{23}$ by Pehrrson et al (144-4500 pg/mL, Immunodiagnostix assay), ${ }^{22}$ and by Wreje et al $(20-255 \mathrm{ng} / \mathrm{L}$, Genentech reagents). ${ }^{34}$ Just as all these studies reported 1 to several participants with unexpectedly high SRCs, our study also revealed outliers. Four athletes had values greater than $1 \mathrm{SD}$ 
above the mean $(>9.38 \mathrm{pg} / \mathrm{mL})$ and 3 had values greater than 2 SDs above the mean $(>16.22 \mathrm{pg} / \mathrm{mL})$. However, all samples had an $\mathrm{SRC}<150 \mathrm{pg} / \mathrm{mL}$, which is consistent with the SRCs previously reported for nonconceptive menstrual cycles. ${ }^{13}$ It is possible that the variation between our SRCs and those previously reported could be explained by a difference in the specificity of the various assays that have been used in these different studies. The relatively new R\&D Systems assay (launched in August 2007) used in this study may be more specific for Relaxin-2, which would explain why our levels were lower than those previously reported. The R\&D assay reports no significant cross-reactivity or interference with human insulinlike growth factor (IGF)-1, IGF-2, Insulin (aa 25-110), Insulin (pro) K (aa 25-110) N His, IGF-3, Relaxin-1, Relaxin-3. However, the majority of previously used assays do not report their level of specificity or cross-reactivity profiles. Only a couple have reported having no cross reactivity with insulin, ${ }^{22,23}$ or IGF- $1 .{ }^{23}$ Lastly, this difference could also reflect a sustained increase in SRC among primi- or multiparous women, which makes their SRCs significantly higher than those of nulligravidae women.

Also as expected, there was a significant difference between mean SRC and SPC among participants who used hormonal contraceptives and those who did not. Hormonal contraceptives suppress ovulation and therefore prevent the formation of a corpus luteum and subsequently prevent the production of relaxin and progesterone. Consequently, it is logical that women on hormonal contraceptives would have lower levels of relaxin and progesterone.

The primary challenge of this study was the timing of the venipuncture to ensure that the serum hormone concentration results could be compared across groups. We attempted to standardize this process by having a set window (days 21-24) for venipuncture among the hormonal contraceptive group and days 7 to 10 after a positive LH test in those not on hormonal contraceptives. However, given that approximately $28 \%$ of the participants in the group not on hormonal contraceptives had SPCs below the $3.3 \mathrm{ng} / \mathrm{mL}$ threshold for determining ovulation, it is likely that they were either having anovulatory cycles or that the samples were drawn in the follicular phase. Conversely, it was also interesting to find that approximately $30 \%$ of participants on hormonal contraceptives had ovulatory cycles as indicated by $\mathrm{SPC}>3.3 \mathrm{ng} / \mathrm{mL}$. This could represent a failure rate in the use of the hormonal contraceptives which, however, would be twice as high as typical use failure rates and is therefore unlikely to be explained completely by $\mathrm{COC}$ misuse. It is more likely that some of the higher SPCs in this group were from adrenally produced progesterone.

\section{Conclusions}

This study has reinforced the strong correlation between progesterone and relaxin levels and corpus luteum production. The finding that hormonal contraceptive use attenuates serum progesterone and relaxin levels is also significant. Should future investigations establish a link between relaxin levels and ligamentous injury among women, our results underscore the significant role that hormonal contraceptives can play in decreasing relaxin levels. Future studies should continue to characterize the levels and behavior of relaxin among young nulligravidae women in addition to the variation in cross-reactivity and sensitivity among relaxin assays to improve the uniformity of SRC quantitation.

\section{Acknowledgments}

Special thanks to Alex Sox Harris, PhD for providing his statistical expertise, and to Hillary Braun, Elizabeth Robinson, Melissa Vogelsong, Nicole Ourada, and Michelle Smith for their assistance with participant recruitment and data collection. This study was funded by the Stanford Department of Orthopaedic Surgery and the Stanford School of Medicine Medical Scholars Research Fellowship Program.

\section{Disclosure}

The authors declare no conflicts of interest.

\section{References}

1. Sherwood OD. Relaxin's physiological roles and other diverse actions. Endocr Rev. 2004;25(2):205-234.

2. Van der Westhuizen ET, Halls ML, Samuel CS, et al. Relaxin family peptide receptors-from orphans to therapeutic targets. Drug Discov Today. 2008;13(15-16):640-651.

3. Hayes ES. Biology of primate relaxin: a paracrine signal in early pregnancy? Reprod Biol Endocrinol. 2004;2:36.

4. Hansell DJ, Bryant-Greenwood GD, Greenwood FC. Expression of the human relaxin $\mathrm{H} 1$ gene in the decidua, trophoblast, and prostate. J Clin Endocrinol Metab. 1991;72(4):899-904.

5. McGowan BM, Stanley SA, Donovan J, et al. Relaxin-3 stimulates the hypothalamic-pituitary-gonadal axis. Am J Physiol Endocrinol Metab. 2008;295(2):E278-E286.

6. Sakbun V, Ali SM, Greenwood FC, Bryant-Greenwood GD. Human relaxin in the amnion, chorion, decidua parietalis, basal plate, and placental trophoblast by immunocytochemistry and northern analysis. $J$ Clin Endocrinol Metab. 1990;70(2):508-514.

7. Blankenship T, Stewart DR, Benirschke K, King B, Lasley BL. Immunocytochemical localization of nonluteal ovarian relaxin. J Reprod Med. 1994;39(4):235-240.

8. Bryant-Greenwood GD, Rutanen EM, Partanen S, Coelho TK, Yamamoto SY. Sequential appearance of relaxin, prolactin and IGFBP-1 during growth and differentiation of the human endometrium. Mol Cell Endocrinol. 1993;95(1-2):23-29. 
9. MacLennan AH, Grant P, Borthwick AC. Relaxin and relaxin c-peptide levels in human reproductive tissues. Reprod Fertil Dev. 1991;3(5): 577-583.

10. Schmidt CL, Sarosi P, Steinetz BG, et al. Relaxin in human decidua and term placenta. Eur J Obstet Gynecol Reprod Biol. 1984;17(2-3): 171-182.

11. Garibay-Tupas JL, Okazaki KJ, Tashima LS, Yamamoto S, Bryant-Greenwood GD. Regulation of the human relaxin genes H1 and H2 by steroid hormones. Mol Cell Endocrinol. 2004 30;219(1-2): $115-125$.

12. Glock JL, Nakajima ST, Stewart DR, Badger GJ, Brumsted JR. The relationship of corpus luteum volume to relaxin, estradiol, progesterone, 17-hydroxyprogesterone and human chorionic gonadotropin levels in early normal pregnancy. Early Pregnancy. 1995;1(3):206-211.

13. Stewart DR, Celniker AC, Taylor CA Jr, Cragun JR, Overstreet JW, Lasley BL. Relaxin in the peri-implantation period. J Clin Endocrinol Metab. 1990;70(6):1771-1773.

14. Weiss G, O’Byrne EM, Hochman J, Steinetz BG, Goldsmith L, Flitcraft JG. Distribution of relaxin in women during pregnancy. Obstet Gynecol. 1978;52(5):569-570.

15. Koay ES, Too CK, Greenwood FC, Bryant-Greenwood GD. Relaxin stimulates collagenase and plasminogen activator secretion by dispersed human amnion and chorion cells in vitro. $J$ Clin Endocrinol Metab. 1983;56(6):1332-1334.

16. Wiqvist I, Norstrom A, O’Byrne E, Wiqvist N. Regulatory influence of relaxin on human cervical and uterine connective tissue. Acta Endocrinol (Copenh). 1984;106(1):127-132.

17. Qin X, Garibay-Tupas J, Chua PK, Cachola L, Bryant-Greenwood GD. An autocrine/paracrine role of human decidual relaxin. I. Interstitial collagenase (matrix metalloproteinase-1) and tissue plasminogen activator. Biol Reprod. 1997;56(4):800-811.

18. MacLennan AH. The role of the hormone relaxin in human reproduction and pelvic girdle relaxation. Scand J Rheumatol Suppl. 1991;88: $7-15$.

19. Word RA, Li XH, Hnat M, Carrick K. Dynamics of cervical remodeling during pregnancy and parturition: mechanisms and current concepts. Semin Reprod Med. 2007;25(1):69-79.

20. Chen B, Wen Y, Yu XY, Polan ML. Relaxin increases elastase activity and protease inhibitors in smooth muscle cells from the myometrium compared with cells from leiomyomas. Fertil Steril. 2009; 91(4 Suppl):1351-1354.

21. Kristiansson P, Samuelsson E, von Schoultz B, Svardsudd K. Reproductive hormones and stress urinary incontinence in pregnancy. Acta Obstet Gynecol Scand. 2001;80(12):1125-1130.
22. Pehrsson M, Westberg L, Landen M, Ekman A. Stable serum levels of relaxin throughout the menstrual cycle: a preliminary comparison of women with premenstrual dysphoria and controls. Arch Womens Ment Health. 2007;10(4):147-153.

23. Binder C, Simon A, Binder L, et al. Elevated concentrations of serum relaxin are associated with metastatic disease in breast cancer patients. Breast Cancer Res Treat. 2004;87(2):157-166.

24. Garber SL, Mirochnik Y, Brecklin CS, et al. Relaxin decreases renal interstitial fibrosis and slows progression of renal disease. Kidney Int. 2001;59(3):876-882.

25. Kristiansson $\mathrm{P}$, Holding $\mathrm{C}$, Hughes $\mathrm{S}$, Haynes D. Does human relaxin-2 affect peripheral blood mononuclear cells to increase inflammatory mediators in pathologic bone loss? Ann N Y Acad Sci. 2005;1041: 317-319.

26. Stewart DR, Sherick P, Kramer S, Breining P. Use of relaxin in orthodontics. Ann N Y Acad Sci. 2005;1041:379-387.

27. Blecher AM, Richmond JC. Transient laxity of an anterior cruciate ligament-reconstructed knee related to pregnancy. Arthroscopy. 1998; 14(1):77-79.

28. Dragoo JL, Padrez K, Workman R, Lindsey DP. The effect of relaxin on the female anterior cruciate ligament: analysis of mechanical properties in an animal model. Knee. 2009;16(1):69-72.

29. Dragoo JL, Lee RS, Benhaim P, Finerman GA, Hame SL. Relaxin receptors in the human female anterior cruciate ligament. Am J Sports Med. 2003;31(4):577-584.

30. Galey S, Konieczko EM, Arnold CA, Cooney TE. Immunohistological detection of relaxin binding to anterior cruciate ligaments. Orthopedics. 2003;26(12):1201-1204.

31. Damen L, Buyruk HM, Guler-Uysal F, Lotgering FK, Snijders CJ, Stam HJ. Pelvic pain during pregnancy is associated with asymmetric laxity of the sacroiliac joints. Acta Obstet Gynecol Scand. 2001;80(11): 1019-1024.

32. Dumas GA, Reid JG. Laxity of knee cruciate ligaments during pregnancy. J Orthop Sports Phys Ther. 1997;26(1):2-6.

33. Arnold C, van Bell C, Rogers V, Cooney T. The relationship between serum relaxin and knee joint laxity in female athletes. Orthopedics. 2002;25(6):669-673.

34. Wreje U, Kristiansson P, Aberg H, Bystrom B, von Schoultz B. Serum levels of relaxin during the menstrual cycle and oral contraceptive use. Gynecol Obstet Invest. 1995;39(3):197-200.
International Journal of Women's Health

\section{Publish your work in this journal}

The International Journal of Women's Health is an international, peerreviewed open-access journal publishing original research, reports, reviews and commentaries on all aspects of women's healthcare including gynecology, obstetrics, and breast cancer. Subject areas include: Chronic conditions (migraine headaches, arthritis, osteoporosis);

\section{Dovepress}

Endocrine and autoimmune syndromes; Sexual and reproductive health; Psychological and psychosocial conditions. The manuscript management system is completely online and includes a very quick and fair peer-review system. Visit http://www.dovepress.com/ testimonials.php to read real quotes from published authors. 